\title{
The Secrets of the Mediterranean Diet. Does [Only] Olive Oil Matter?
}

\author{
Alessandra Mazzocchi ${ }^{1,2}$, Ludovica Leone ${ }^{1,2}$, Carlo Agostoni ${ }^{1,2,3, *(D)}$ and \\ Isabella Pali-Schöll 4,5 \\ 1 Department of Clinical Sciences and Community Health, University of Milan, 20126 Milan, Italy; \\ alessandra.mazzocchi@unimi.it (A.M.); ludovica.leone@unimi.it (L.L.) \\ 2 SIGENP (Italian Society of Pediatric Gastroenterology, Hepatology, and Nutrition), via Libero Temolo \\ 4 (Torre U8), 20126 Milan, Italy \\ 3 Pediatric Intermediate Care Unit, Fondazione IRCCS Ca' Granda Ospedale Maggiore Policlinico, \\ 20126 Milan, Italy \\ 4 Center for Pathophysiology, Infectiology and Immunology, Institute of Pathophysiology and Allergy \\ Research, Medical University of Vienna, 1090 Vienna, Austria; isabella.pali@vetmeduni.ac.at \\ 5 Comparative Medicine, The interuniversity Messerli Research Institute, University of Veterinary Medicine, \\ Medical University and University Vienna, 1090 Vienna, Austria \\ * Correspondence: carlo.agostoni@unimi.it; Tel.: +39-02-55032497 or +39-02-50320202
}

Received: 23 October 2019; Accepted: 27 November 2019; Published: 3 December 2019

check for updates

\begin{abstract}
Diet plays a key role in the maintenance and optimal functioning of immune cells. The Mediterranean dietary pattern is an example of a prudent choice of lifestyle and scientifically accepted to help preserve human health by protecting against major chronic and inflammatory diseases. Mediterranean diets (MedDiets) are characteristically high in the consumption of fruits, vegetables and salad, bread and whole grain cereals, potatoes, legumes/beans, nuts, and seeds. Their common central feature is the usage of olive oil as the main source of fat. The health benefits attributed to olive oil are specifically related to extra virgin olive oil (EVOO) intake with its high nutritional quality and multiple positive effects on health. Overall, MedDiets have direct (mono-unsaturated fatty acids (MUFAs), tocopherols, polyphenols) and indirect (low saturated fats, well-balanced linoleic/alpha linolenic acid) effects on the immune system and inflammatory responses. In the present paper, we summarize the current knowledge on the effect of olive oil per se and MedDiets generally on immune-mediated and inflammatory diseases, such as coronary heart disease (CHD)/cardiovascular diseases (CVD), obesity, type-2 diabetes, cancer, asthma, and allergies.
\end{abstract}

Keywords: allergy; cancer; CHD/CVD; fresh food; inflammation; metabolic syndrome; mono-unsaturated fatty acids; obesity; olive oil; traditional

\section{Introduction}

The term immunomodulation refers to any therapeutic intervention directed at modifying the immune response. At birth, the immune system is immature, but it develops with age, antigen stimulation, and appropriate nutrition [1]. Diet plays a key role in the maintenance and optimal functioning of immune cells. It is well known that nutrients and nutritional factors can help to preserve good health, influencing all aspects of human biology by connecting nutrient metabolism, gut microbiota, and immune system [2].

For instance, essential fatty acids (EFAs) are important immune regulators. Linoleic acid (LA), the parental $n-6$ polyunsaturated fatty acid (PUFA), is converted in the mammalian body into arachidonic acid (AA) and subsequently may give origin to pro-inflammatory lipid mediators (eicosanoids). On the contrary, from $\alpha$-linolenic acid (ALA), n-3 PUFA eicosapentaenoic acid (EPA) and docosahexaenoic 
acid (DHA) are produced and subsequently converted into anti-inflammatory and/or pro-resolving lipid mediators (resolvins and protectins) [3].

The prevalence in the membranes of inflammatory cells of either AA, or EPA/DHA, may influence human immunologic conditions, and since $n-3$ and $n-6$ PUFAs compete for the same metabolic pathways, an increase of $n-3$ PUFA rather than $n-6$ PUFA will enhance an anti-inflammatory response.

Vitamins and trace elements are also involved in the maintenance of the immune response. The Mediterranean dietary pattern is not only exemplified as a prudent choice of lifestyle, but also as a scientifically accepted mechanism that helps to preserve human health and protect against major chronic diseases. Mediterranean-style diets are considered beneficial for the prevention and/or treatment of obesity, type-2 diabetes, and inflammatory disorders [4].

In the present paper, we summarize the current knowledge on the effect of the Mediterranean diet (MedDiet) with special focus on extra virgin olive oil (EVOO) on immune-mediated inflammatory diseases (IMID) and cardiovascular diseases (CVD).

\section{Definition and Composition of Mediterranean Diet}

The term "Mediterranean diet" (MedDiet) refers to the pattern of the diet that was common in the 1960s in the olive tree-growing countries around the Mediterranean Sea, especially Greece/Crete and the south of Italy. At that time, the Seven Countries Study showed that mortality due to coronary heart diseases in the Mediterranean area was 2-3 times lower than in North Europe and the USA [5]. The time point is important to consider, because in many of these countries the diet has changed since then and is now similar to the so-called "Western diet" of the USA and Northern Europe.

More than 16 countries border the Mediterranean Sea, the inhabitants of which follow a different dietary pattern according to cultural, social, or religious habits. However, there is an overall Mediterranean dietary pattern (comprehensively reviewed in [6]), which is characterized by the high consumption of fruits, vegetables and salad, bread and whole grain cereals, potatoes, legumes/beans, nuts, and seeds. Dairy products, like cheese and yogurt, fish, shellfish, and poultry are consumed in low to moderate amounts, whereas little red and processed meat is eaten, and eggs are consumed up to four times a week. The need for salt and fat for aromatic purposes is lowered by wide usage of herbs and spices. Wine and/or other fermented beverages are consumed in low to moderate amounts, accompanying the meals.

Finally, a common and central feature of all variations of the MedDiet is the usage of olive oil as the main source of fat, with mainly monounsaturated fatty acids.

Altogether, this diet is low in saturated fatty acids and provides high amounts of antioxidants, carbohydrates, and fiber and, above all, a high content of monounsaturated fatty acids and $n-3$ PUFAs, mainly derived from olive oil as alpha-linolenic acid and long-chain PUFAs from fish, particularly in certain areas.

Apart from the food groups consumed, food is produced traditionally and marketed locally, and is mostly used and eaten shortly after harvesting. Eating in a pleasant, familiar environment, having a rest after the meal and also being physically and socially active completes the dietary pattern to a healthy lifestyle (Figure 1). Recent papers also provide evidence that the MedDiet-beyond its benefits for human health-has a low adverse effect on the environment and represents an affordable model of sustainability [7].

The composition of a MedDiet can also be broken down to the actual macro- and micronutrient content (Table 1). It was shown that the content in MedDiet was nearly totally according to the actual guidelines and recommendations for daily nutrient uptake even for adults living in the US (as given in Table 1). Taking a closer look into the composition of a MedDiet, and what was especially seen in Greece [8], the resulting n-6: $n-3$ ratio is 2:1 compared to a ratio of 15:1 and higher in Western and Northern Europe or the USA, where currently a ratio of 5:1 is recommended. In addition to the desired fatty acids (FA) composition, the Greek and Cretan non-fat components include considerable amounts of antioxidants, phytochemicals, and phenolic compounds, together with vitamin $C$ and $E, \beta$-carotene 
as precursor of vitamin A, glutathione, resveratrol, selenium, phytoestrogens, and folate. The main dietary sources providing these valuable compounds are olive oil, wine, fish, and vegetables, especially tomatoes, onions, garlic, and herbs like oregano, mint, rosemary, parsley, and dill [8].

\section{rediscover goodness OLDWAYS

\section{Mediterranean Diet Pyramid}

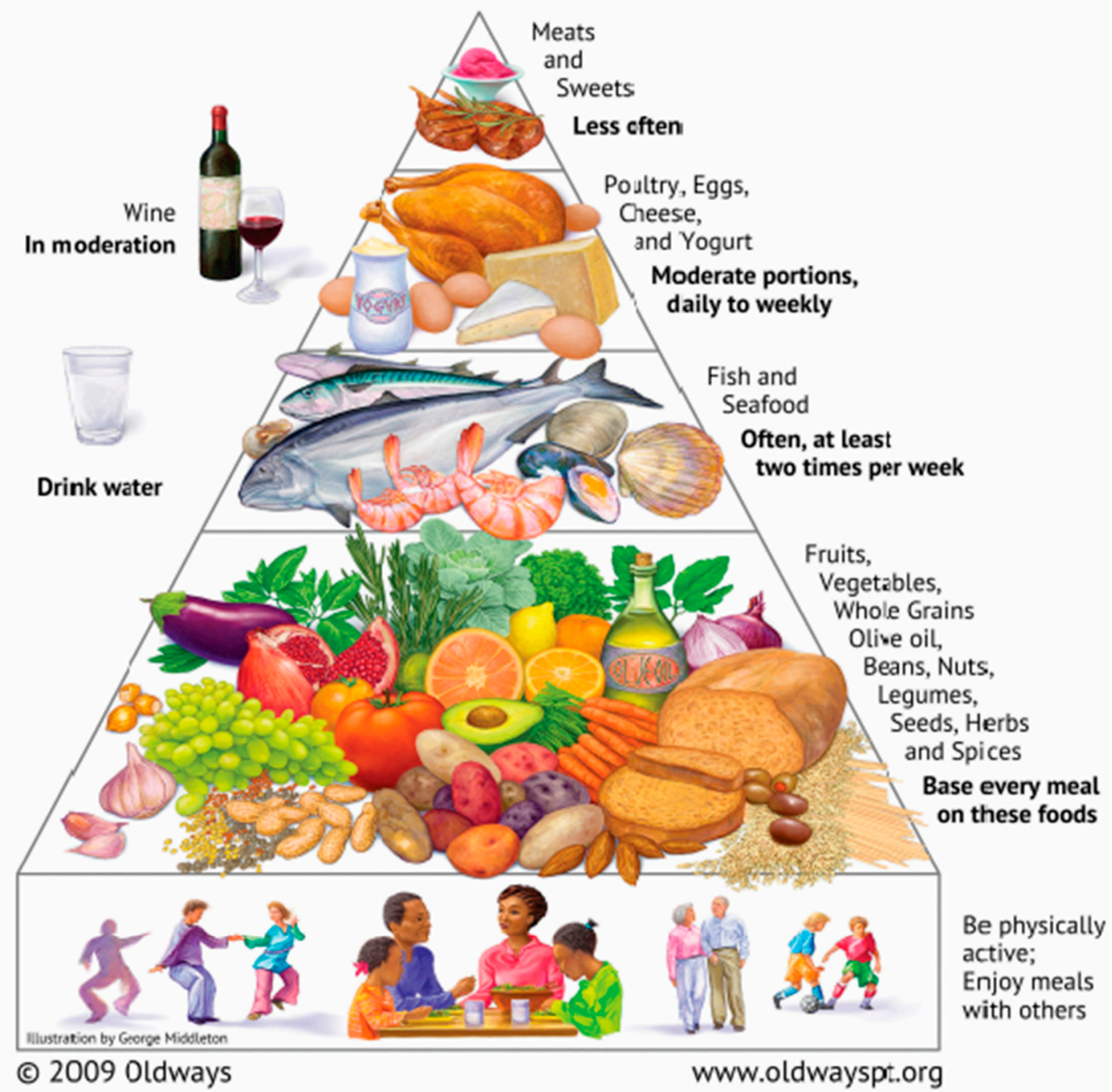

Figure 1. The Mediterranean Diet Pyramid with olive oil as an important nutritional fat source. Image credit: Copyright by Oldways and [9], used with kind permission. 
Table 1. Nutrients in a Mediterranean diet compared to the guidelines for daily nutrient uptake.

\begin{tabular}{lll}
\hline Nutrients & Distribution in Mediterranean Diet & $\begin{array}{l}\text { Recommendations for } \\
\text { 19-50-Year Old Americans * }\end{array}$ \\
\hline Total fat (\% of total calories) & $25-35$ & $20-35$ \\
Saturated fat (\% of total calories) & $\leq 8$ & $\leq 10$ \\
Cholesterol (mg) & $\leq 300$ & Not restricted \\
Sodium $(\mathrm{mg})$ & $\leq 2300$ & $\leq 2300$ \\
Potassium $(\mathrm{mg})$ & $\geq 4700$ & $\geq 4700$ \\
Carbohydrates (\% of total calories) & $45-65$ & $45-65$ \\
Protein $(\%$ of total calories) & $10-35$ & $10-35$ \\
Vitamin A ( $\mu \mathrm{g})$ & $\geq 900$ & women: $700 ;$ men: 900 \\
Vitamin C $(\mu \mathrm{g})$ & $\geq 90$ & women: $75 ;$ men: 90 \\
Calcium $(\mathrm{mg})$ & $\geq 1200$ & $\geq 1000$ \\
Iron $(\mathrm{mg})$ & $\geq 18$ & women: $18 ;$ men: 8 \\
\hline
\end{tabular}

Table adapted from [10] (with kind permission). * Recommendations according to the U.S. Department of Health and Human Services and the U.S. Department of Agriculture. 2015-2020 Dietary Guidelines for Americans. 8th Edition. December 2015. Available at [11].

\section{Mediterranean Diet and Diet Diversity}

An additional measure to consider when defining the value of a certain nutritional pattern-for health, growth, and immunological events-is diet diversity [12]. We have summarized the influence of diet diversity on asthma and allergy development in a position paper [13], where the definition of diet diversity is "...the number of different foods or food groups consumed over a given reference time period". Such an independent measure based on desirable dietary patterns is the Mediterranean Diet Score [14], suggested by Trichopoulou et al. in 2003 [15]. Here, nine components are considered, which are vegetables, legumes, fruits and nuts, cereals, fish and seafood, ratio of mono-unsaturated fatty acids (MUFA):SFA, meat and meat products, dairy products, and moderate alcohol consumption. A point is scored when a person takes in more than the median of the same sex group from the first six components listed above (which are according to MedDiet), another point when taking in lower than the median from meat and dairy products (not consistent with MedDiet), and another when alcohol intake is moderate (which is max $25 \mathrm{~g} /$ day for female and $50 \mathrm{~g} /$ day for male individuals). Therefore, the maximum possible points are nine, and the diversity score can range from zero to nine. Several variations of the MedDiet Score have been created to be applied in studies with different populations, also outside the Mediterranean area, providing the possibility to measure adherence to MedDiet [6], like the alternate MedDiet score [16], the 14-Point MedDiet Adherence Screener (MEDAS) [17], the MedDiet 55 Score (MD55) [18], and the Med Adequacy Index (MAI) [19]. These indices all vary for which foods are considered as being in one group (e.g., nuts and legumes together, all kinds of meat within one group or just red meat, and separately considering usage of olive oil). In summary, the MedDiet reflects a healthy eating pattern, which has been found to protect against several inflammatory diseases like coronary heart disease (CHD) and stroke [16].

\section{Mediterranean Diet Contribution to Immunomodulation}

\subsection{Bioactive Components}

Olive oil is the traditional symbol of the Mediterranean diet, representing the primary source of fat. The health benefits attributed to the consumption of olive oil are specifically related to extra virgin olive oil (EVOO), which is considered a key bioactive food because of its high nutritional quality (Table 2) [20].

Traditionally, the high content of MUFAs was considered to be responsible for the protective effects of EVOO. Indeed, the concentration of the MUFA oleic acid (C18:1 n-9) is much higher (55-83\%) than that of the other fatty acids (linoleic, palmitic, or stearic acids), which range between $3 \%$ and $21 \%$. However, now it is known that most of these benefits are related to the minor components in the unsaponifiable fraction (about $2 \%$ of oil weight), including phenolic compounds, phytosterols, 
tocopherols, and pigments. This fraction is responsible for EVOO oxidative stability, sensorial attributes (such as bitterness and pungency) and its unique fragrance [21]. The presence of these molecules depends on the grade of maturation of the fruit, the cultivar variety, the climate of the area of cultivation, and the type of oil extraction processes [22]. Phenolic concentration in EVOO range from 50 to $800 \mathrm{mg} / \mathrm{kg}$ [23]. The phenolic content consists of various phenolic classes, such as phenolic acids (vanillic, coumaric, caffeic, protocatechuic, p-hydroxybenzoic, ferulic), lignans (acetoxypinoresinol, pinoresinol), flavones (apigenin, luteolin), flavone glycosides (luteolin-7-O-glucoside, apigenin-7-O-glucoside), phenolic alcohols (tyrosol, hydroxytyrosol), and secoiridoids (oleacein, oleocanthal, oleuropein, p-HPEA-EA). The predominant phenolic compound found in olive oil is made up by oleuropein and its hydrolytic breakdown products, hydroxytyrosol and tyrosol [23]. Their contribution to human health is very wide: they exert efficacy in prevention and treatment of chronic diseases thanks to their anti-inflammatory, antioxidant, neuroprotective, and immunomodulatory activities [2].

In 2011, the European Food Safety Authority (EFSA) published a health claim related to polyphenols in olive oil and their possible protection of blood lipids against oxidative stress. Accordingly, the panel established that $5 \mathrm{mg}$ of hydroxytyrosol and its derivatives (e.g., oleuropein complex and tyrosol) in olive oil should be consumed daily in the context of a balanced diet [24] for sufficient avoidance of oxidative damage [25]. Although, to the best of our knowledge, there are no studies to prove in direct comparison a difference between native EVOO vs. adulterated or poor-quality oils, we assume that the multiple health benefits attributed to the contained bioactive molecules of EVOO might at least be lost, and in the worst case threaten the health of consumers.

Table 2. Nutritional components present in extra virgin olive oil.

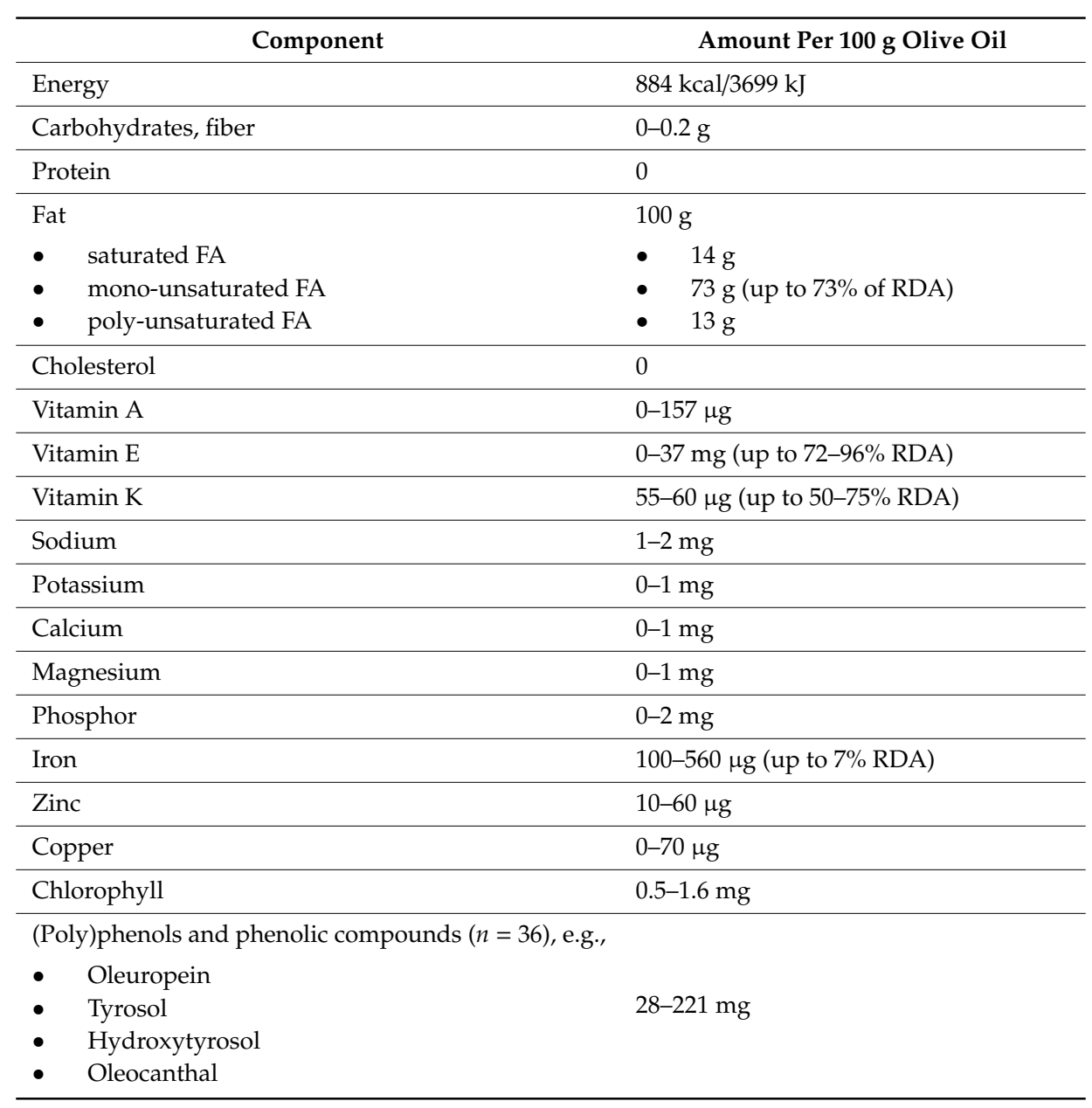

Values might differ considerably according to olive cultivar, climate conditions, and production process of oil [24]. Data taken and combined from [26-28]. 


\subsection{Cardiovascular Diseases/Coronary Heart Diseases}

There is an abundancy of literature that provides insights into the mechanisms underlying the prevention of CHD by EVOO [29,30]. The overall dietary pattern within the MedDiet plays an additional role, e.g., high fiber positively affecting the microbiome, and even more the myriads of non-fat micro-components. Therefore, the dietary pattern as well as the diet diversity per se present a healthy and balanced composition with energy, macro- and micronutrients, perfectly fitting to most nutritional guidelines.

Among the beneficial properties of EVOO, its antioxidant effects have been intensively studied because of the link between oxidative stress and atherosclerotic diseases. Oxidative stress is implicated in the pathogenesis of several risk factors of atherosclerosis including hypertension, diabetes, and metabolic syndrome. Guasch-Ferré et al. reported in an observational study that increases of $10 \mathrm{~g} /$ day in EVOO intake were associated with a $10 \%$ reduction in the risk of cardiovascular events [31]. Several studies suggested that phenolic compounds are important for the cardiovascular benefits of EVOO and showed an improvement of antioxidant capacity $[32,33]$ and a reduction of all markers of oxidative stress [34,35]. A clinical trial on healthy volunteers analyzed the effect on inflammation and oxidative status after administration of $25 \mathrm{~g}$ of phenol-rich EVOO with high content of hydroxyphenylethanol [36]. The results highlighted a significant reduction of oxidized LDL, malondialdehyde, triglycerides, and visceral adiposity index. Furthermore, the expression of inflammation and oxidative stress-related genes, as superoxide dismutase 1, upstream transcription factor 1 , and catalase was significantly upregulated.

Moreover, EVOO supplemented to a Mediterranean lunch is capable of blunting oxidative stress by regulating platelet oxidative stress and endothelial dysfunction, as demonstrated by a reduction in Nox2 activation and soluble E-selectin/VCAM1 release, respectively [35]. In humans, the role of EVOO as an anti-atherosclerotic nutrient is also supported by its ability to modulate expression of atherosclerosis-related genes in which LDL oxidation is involved. The anti-inflammatory effect in the vascular wall may be another relevant mechanism, linking EVOO and modulation of cardiovascular events.

Consumption of a Mediterranean-style diet supplemented with EVOO also in patients with the metabolic syndrome was associated with a significant reduction of systemic vascular inflammation markers (IL-6, IL-7, IL-aa18, and hs-CRP) [37]. Long- and short-term studies demonstrated that EVOO supplementation was also associated with a significant decrease in inflammatory markers, namely Thromboxane-B2 (TXB2) and Leukotriene-B4, which confirmed the anti-thrombotic and anti-inflammatory effects of EVOO in a postprandial state [32]. Studies on subjects at high cardiovascular risk showed that after EVOO supplementation, the blood pressure values, both systolic and diastolic, are reduced $[38,39]$. In summary, the data demonstrate that EVOO intake is associated with a beneficial impact on CVDs. Intervention studies are consistent with these beneficial effects, as supported by the ability of EVOO to prevent or reduce the inflammatory processes associated with chronic-degenerative diseases, such as cardiovascular-cerebral diseases and cancer.

\subsection{Metabolic Syndrome with Lipid and Glycemic Control}

Positive results were also recorded in a two-year study on subjects with metabolic syndrome [37], showing a decrease in blood pressure values only in women with moderate hypertension supplemented with EVOO and not in the control low-fat diet group [39].

Hypercholesterolemia is another risk factor for CVD. MedDiet has been associated with a reduction in atherogenic cholesterol LDL-C and non-high-density lipoprotein cholesterol (non-HDL-C) levels [40].

Hernáez et al. showed that a one-year intervention with a MedDiet, especially when enriched with virgin olive oil, improves several HDL functions such as cholesterol efflux capacity, cholesterol metabolism, anti-oxidant/anti-inflammatory properties, and vasodilatory capacity in individuals at high cardiovascular risk [41]. Similarly, Covas et al. found that after consuming phenolic olive oils, 
HDL-C increases, whereas the TC/HDL-C ratio decreases with a concomitant decrease in LDL-C/HDL-C ratio and triglycerides [42].

Nutritional interventions with EVOO may have a positive effect on plasma glucose and lipids. Changes of glycaemic and lipid profiles might have an effect on cardiovascular disease by promoting or aggravating the atherosclerotic process. MedDiet supplemented with EVOO has a beneficial effect on the postprandial metabolic profile by decreasing blood glucose, LDL-C, and ox-LDL and increasing insulin levels in healthy subjects [43]. Furthermore, $10 \mathrm{~g}$ of EVOO supplemented to a Mediterranean lunch are able to improve post-prandial glycaemic profiles in patients with impaired fasting glucose. The mechanisms accounting for the positive effect of EVOO are related to incretins up-regulation, as EVOO reduces dipeptidyl peptidase- 4 activity with a consequent increase in glucagon-like peptide-1 concentration, which regulates postprandial glycaemia by up-regulating insulin secretion [44].

Changes in glycaemic and lipid profiles were observed also in patients with the metabolic syndrome. After 2 years, patients in the intervention group (MedDiet supplemented with EVOO) had significant decreases in the levels of glucose, insulin, total cholesterol, and triglycerides, and a significant increase in the levels of HDL, all of which were greater than the control group [37].

Polyphenols might affect glucose metabolism via an inhibition of carbohydrate digestion and absorption, a reduction of glucose release from the liver, or a stimulation of glucose uptake in peripheral tissues. With their antioxidative properties, they might diminish the production of advanced glycosylated end products, such as $\mathrm{HbA1cAs}$, be a potential mechanism of action, and lead to reductions in the glycemic load (especially when replacing carbohydrates with MUFA). The consecutive attenuation in insulin secretion, as well as increased insulin sensitivity, may explain the beneficial effects of MUFA on glycemic control [45].

Summing up, recent data suggest that a Mediterranean-style diet is a possible strategy for the treatment of metabolic syndrome and the reduction of the associated cardiovascular risk.

Moreover, EVOO supplementation provides an improvement of the post-prandial glucose and lipid profile, and this effect represents an important additional mechanism supporting the role of EVOO as an anti-atherosclerotic nutrient [43].

\subsection{Diabetes Mellitus Type 2}

Recent meta-analyses of randomized controlled trials reported beneficial effects on metabolic risk factors in T2DM patients after replacing carbohydrates ( $~ 5-10 \%$ of total energy intake) in general with MUFA [46-48]. The clearest evidence that EVOO may prevent T2DM can be found in the PREDIMED study in which glucose metabolism improved and body weight decreased in 80 cases of new-onset diabetes allocated to the MedDiet + EVOO [3,49,50]. Moreover, specific components of EVOO can also be considered as novel candidates for improving the glycaemic profile in patients with diabetes mellitus. In an interventional study, authors provide evidence that oleuropein lowers postprandial glycaemia by reduction of Nox2 activity in healthy subjects [51].

\subsection{Cancer}

EVOO seems to have a protective role against cancer. For instance, oncology researchers have discovered that oleic acid suppresses the over-expression of the oncogene HER2, which is critical to the etiology, invasion, progression, and metastasis especially of human mammary carcinoma [52]. A recent trial investigated whether hydroxytyrosol improves the antitumor response of women with breast cancer undergoing neoadjuvant chemotherapy, influencing plasma levels of molecules involved in cell proliferation, apoptosis, and metastasis (e.g., tissue inhibitor of metalloproteinases (TIMP-1). Data showed that in women receiving a dietary supplement with $15 \mathrm{mg} /$ day of hydroxytyrosol combined with a specific chemotherapy treatment, the plasma levels of TIMP-1 decreases [53].

In vitro studies examined the protective effect of bioactive compounds of oleic acid against neoplastic diseases. One trial demonstrated, for the first time, that olive oil minor components (hydroxytyrosol, oleuropein, pinoresinol, squalene, and maslinic acid) are capable of reversing the 
proliferative effect induced by oleic acid on intestinal epithelial cell cultures [54]. Another recent trial evaluated the in vitro anticancer and chemopreventive potential of two EVOO extracts (tyrosol and hydroxytyrosol) and secoiridoid derivatives (oleocanthal and oleacein) on cutaneous non-melanoma skin cancer models. Results demonstrated that phenolic EVOO extracts can block molecular steps that occur after the initial UV radiation exposure and before or during tumor development. In particular, these findings showed that secoiridoid derivatives contribute more than simple phenols to the mechanism of action of EVOO extracts [55].

A systematic review and a metanalysis of 19 case-control studies, including 23,340 controls and 13,800 patients, concluded that high EVOO intake has a protective role on the risk of breast cancer $(\log \mathrm{OR}=-0.4595 \% \mathrm{CI}-0.78$ to -0.12$)$, and digestive cancer $(\log \mathrm{OR}=-0.36,95 \% \mathrm{CI}-0.50$ to -0.21$)$ compared with the lowest intake [56].

Epidemiological studies have revealed that women who follow a MedDiet have lower rates of breast cancer than those who did not $[57,58]$. EVOO has been shown to contribute to the prevention of a dangerous form of skin cancer, malignant melanoma [59]. With regards to melanoma, the antioxidant properties of EVOO help to counter oxidation by the sun. Researchers have established the oleocanthal ability to provide potent anti-inflammatory properties, which inhibit COX enzymes in the same way as the non-steroidal anti-inflammatory drug (NSAID) ibuprofen [60]. For the first time, a study revealed that oleocanthal may provide anti-prolific activity against melanoma cells by inhibiting melanoma cell growth in a concentration-dependent manner, that is, the more the cells are exposed to oleocanthal, the less they proliferate and become cancer causing.

\subsection{Weight Control}

Chronic obesity is a situation of chronic systemic inflammation [61] and can contribute, for instance, to the development and/or severity of asthmatic and probably also allergic diseases [62]. Weight control, therefore, is of uttermost importance, and MedDiet could contribute also here. However, there is limited, but suggestive, evidence for the effects on the body weight regarding the reduction of fat mass with consequent increases of muscle mass. A trial evaluated the effects of hydroxytyrosol on the expression of genes and microRNAs involved in TNF- $\alpha$ and macrophage-induced inflammatory and dysmetabolic phenotype of human adipocytes. Results demonstrated that hydroxytyrosol can modulate the adipocyte gene expression profile through mechanisms involving a reduction of oxidative stress and NF- $\mathrm{KB}$ inhibition and may blunt macrophage recruitment, preventing the deregulation of pathways involved in obesity-related diseases [63]. Further dietary intervention studies in humans are needed [64].

\subsection{Allergic Diseases}

Recent systematic reviews and meta-analysis suggest that the Mediterranean dietary pattern is inversely related to asthma symptoms in children; in particular, when considering all studies together, data showed that a MedDiet is a protective factor for "current wheeze", and "asthma ever" but not for "severe current wheeze" $[65,66]$.

A possible explanation for the beneficial/prophylactic effects regarding asthmatic symptoms is the richness in bioactive compounds that may prevent or limit inflammatory responses in the airways by reducing reactive oxygen species and inhibiting lipid peroxidation.

If we consider olive oil specifically, only one trial is available in the last ten years: it's a population multi-case study of Italian adults, where authors investigated the association of dietary fatty acids and of olive oil with asthma and rhinitis [67]. Results showed that intakes of MUFA and oleic acid were associated with a reduced risk of current asthma (CA), even when they were categorized in quartiles; the subjects in the highest quartile of oleic acid uptake had less than half the risk of having CA compared to those in the lowest quartile. Moreover, authors found that, when considering olive oil intake as a continuous variable, the risk of being a case of CA decreased by $20 \%$ for an increase of $10 \mathrm{~g} /$ day in olive oil intake. 
Another trial investigated the specific role of the phenolic compound hydroxytyrosol (HT) that exerts notable anti-inflammatory effects [68]. The authors studied the ability of HT to increase a Parietaria allergen-induced IL-10 secretion ex vivo in PBMCs from healthy volunteers. This pilot work demonstrated that the co-administration of HT and an allergenic molecule to PBMCs can potentiate a tolerogenic immune response via an increase of IL-10 secretion, suggesting the capability of HT to potentiate a healthy immune response.

Importantly, to confirm the efficacy of a MedDiet in preventing immune-mediated allergic diseases, the worldwide prevalence numbers for allergic rhinoconjunctivitis and asthma underline a possible association, with lower numbers especially in the Eastern Mediterranean, while higher numbers are observed, for instance, in English language countries [69].

EVOO polyphenols can also be used to manage skin inflammatory conditions. In the study by Aparicio-Soto et al., results demonstrated that EVOO phenols exert anti-inflammatory effects on human keratinocytes suppressing key epidermal cytokines [70].

On the whole, convincing epidemiological and experimental literature indicates that olive products may play a key role in the health benefits of the MedDiet, and a model for healthy eating, contributing to a favorable health status and therefore a better quality of life.

\section{Summary}

Does [only] olive oil matter? For sure, olive oil being the main source of fat in a Mediterranean diet (Figure 1) has direct (tocopherols, polyphenols, mono-unsaturated FA) and indirect (lower saturated fats, balanced linoleic/alpha linolenic acid) effects on the immune system and inflammatory responses (Figure 2).

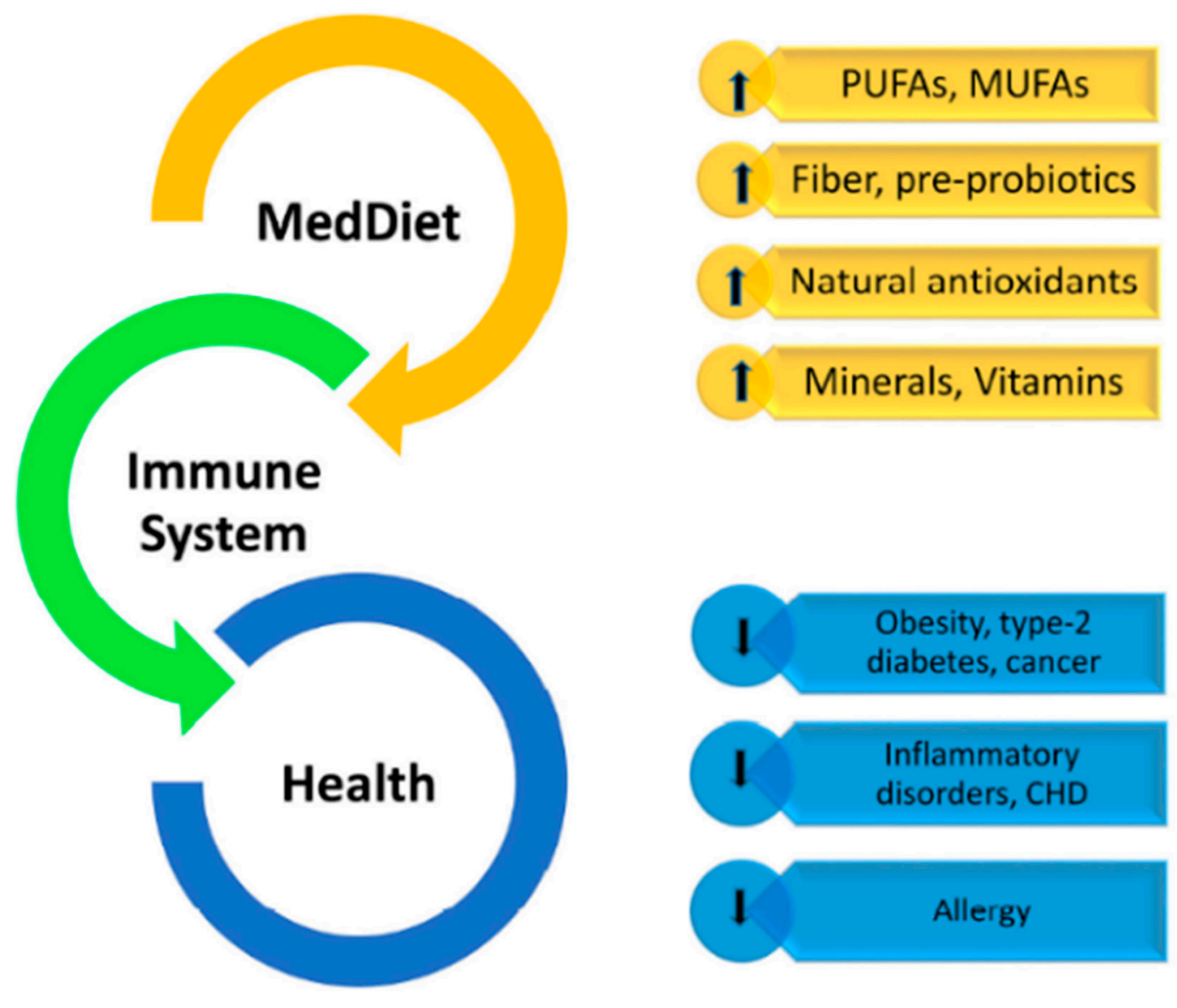

Figure 2. The multistep influence of the Mediterranean diet (MedDiet) on the immune system and related disorders. 
The overall dietary pattern within the MedDiet plays an additional role, e.g., high fiber positively affecting the microbiome, and even more the myriads of non-fat micro-components. Therefore, the dietary pattern as well as the diet diversity per se present a healthy and balanced composition with energy, macro- and micronutrients perfectly fitting to most nutritional guidelines. In addition, environmental, socio-cultural and life-style factors seem to present an uttermost important additional precondition for this diet to be effective in immunomodulation. The food being grown locally and sustainably, being minimally processed and eaten freshly, prepared at home, eaten in a pleasurable familiar conviviality, the moderate consumption of wine, as well as people having a rest after the meal, together with regular physical activity—all these factors seem to be necessary equipment for the MedDiet to positively affect human health. Furthermore, the fact that Mediterranean populations live in environments connected to the sea, coasts, and mountains, allowing them to exercise in everyday life within their millenarian historical evolution, should not be underestimated. Therefore, all these factors need to be considered when performing transferability studies of this diet to people all over the world.

Author Contributions: I.P.-S. wrote the abstract, definition, and composition of the Mediterranean diet and diet diversity including tables, as well as part of the summary. A.M. and L.L. wrote the introduction and the part on Mediterranean diet contributions to immunomodulation, and also proofread and sorted the references. C.A. critically reviewed the paper and made final revisions of the draft. All the authors contributed significantly to the paper and agreed to the manuscript in its current form.

Funding: Research during work for this review was supported by a contribution from the Italian Ministry of Health (IRCCS grant).

Conflicts of Interest: The authors declare no conflict of interest.

\section{References}

1. Mazzocchi, A.; Venter, C.; Maslin, K.; Agostoni, C. The Role of Nutritional Aspects in Food Allergy: Prevention and Management. Nutrients 2017, 9, 850. [CrossRef] [PubMed]

2. Santangelo, C.; Vari, R.; Scazzocchio, B.; De Sanctis, P.; Giovannini, C.; D'Archivio, M.; Masella, R. Anti-inflammatory Activity of Extra Virgin Olive Oil Polyphenols: Which Role in the Prevention and Treatment of Immune-Mediated Inflammatory Diseases? Endocr. Metab. Immune Disord. Drug Targets 2018, 18, 36-50. [CrossRef] [PubMed]

3. Kunisawa, J.; Arita, M.; Hayasaka, T.; Harada, T.; Iwamoto, R.; Nagasawa, R.; Shikata, S.; Nagatake, T.; Suzuki, H.; Hashimoto, E.; et al. Dietary $\omega 3$ fatty acid exerts anti-allergic effect through the conversion to 17,18-epoxyeicosatetraenoic acid in the gut. Sci. Rep. 2015, 5, 9750. [CrossRef] [PubMed]

4. Gotsis, E.; Anagnostis, P.; Mariolis, A.; Vlachou, A.; Katsiki, N.; Karagiannis, A. Health benefits of the Mediterranean Diet: An update of research over the last 5 years. Angiology 2015, 66, 304-318. [CrossRef] [PubMed]

5. Keys, A.; Menotti, A.; Karvonen, M.J.; Aravanis, C.; Blackburn, H.; Buzina, R.; Djordjevic, B.S.; Dontas, A.S.; Fidanza, F.; Keys, M.H.; et al. The diet and 15-year death rate in the seven countries study. Am. J. Epidemiol. 1986, 124, 903-915. [CrossRef] [PubMed]

6. Sanchez-Villegas, A.; Zuzpa, I. A Healthy-Eating Model Called Mediterranean Diet. In The Prevention of Cardiovascular Disease through the Mediterranean Diet; Sanchez-Villegas, A., Sanchez-Tainta, A., Eds.; Elsevier: London, UK; Academic Press: London, UK, 2017.

7. Sáez-Almendros, S.; Obrador, B.; Bach-Faig, A.; Serra-Majem, L. Environmental footprints of Mediterranean versus Western dietary patterns: Beyond the health benefits of the Mediterranean diet. Environ. Health 2013, 12, 118. [CrossRef] [PubMed]

8. Simopoulos, A.P. The Mediterranean diets: What is so special about the diet of Greece? The scientific evidence. J. Nutr. 2001, 131, 3065S-3073S. [CrossRef]

9. Mediterranean Diet. Available online: https://oldwayspt.org/traditional-diets/mediterranean-diet (accessed on 29 November 2019).

10. Mediterranean Diet. Available online: https://www.gbhealthwatch.com/Diet-Mediterranean.php (accessed on 29 November 2019). 
11. Dietary Guidelines for Americans 2015-2020. Available online: http://health.gov/dietaryguidelines/2015/ guidelines/ (accessed on 29 November 2019).

12. Ruel, M.T. Is dietary diversity an indicator of food security or dietary quality? A review of measurement issues and research needs. Food Nutr. Bull. 2003, 24, 231-232. [CrossRef]

13. Venter, C.; Greenhawt, M.; Meyer, R.W.; Agostoni, C.; Reese, I.; du Toit, G.; Feeney, M.; Maslin, K.; Nwaru, B.I.; Roduit, C.; et al. EAACI position paper on diet diversity in pregnancy, infancy and childhood: Novel concepts and implications for studies in allergy and asthma. Allergy 2019. [CrossRef]

14. Trichopoulou, A.; Kouris-Blazos, A.; Wahlqvist, M.L.; Gnardellis, C.; Lagiou, P.; Polychronopoulos, E.; Vassilakou, T.; Lipworth, L.; Trichopoulos, D. Diet and overall survival in elderly people. BMJ 1995, 311, 1457-1460. [CrossRef]

15. Trichopoulou, A.; Costacou, T.; Bamia, C.; Trichopoulos, D. Adherence to a Mediterranean diet and survival in a Greek population. N. Engl. J. Med. 2003, 348, 2599-2608. [CrossRef] [PubMed]

16. Fung, T.T.; Rexrode, K.M.; Mantzoros, C.S.; Manson, J.E.; Willett, W.C.; Hu, F.B. Mediterranean diet and incidence of and mortality from coronary heart disease and stroke in women. Circulation 2009, 119, 1093-1100. [CrossRef] [PubMed]

17. Schroder, H.; Fito, M.; Estruch, R.; Martinez-Gonzalez, M.A.; Corella, D.; Salas-Salvado, J.; Lamuela-Raventos, R.; Ros, E.; Salaverria, I.; Fiol, M.; et al. A short screener is valid for assessing Mediterranean diet adherence among older Spanish men and women. J. Nutr. 2011, 141, 1140-1145. [CrossRef] [PubMed]

18. Panagiotakos, D.B.; Pitsavos, C.; Stefanadis, C. Dietary patterns: A Mediterranean diet score and its relation to clinical and biological markers of cardiovascular disease risk. Nutr. Metab. Cardiovasc. Dis. 2006, 16, 559-568. [CrossRef]

19. Alberti-Fidanza, A.; Fidanza, F. Mediterranean Adequacy Index of Italian diets. Public Health Nutr. 2004, 7, 937-941. [CrossRef]

20. Martín-Peláez, S.; Covas, M.I.; Fitó, M.; Kušar, A.; Pravst, I. Health effects of olive oil polyphenols: Recent advances and possibilities for the use of health claims. Mol. Nutr. Food Res. 2013, 57, 760-771. [CrossRef]

21. Bendini, A.; Cerretani, L.; Carrasco-Pancorbo, A.; Gómez-Caravaca, A.M.; Segura-Carretero, A.; Fernández-Gutiérrez, A.; Lercker, G. Phenolic molecules in virgin olive oils: A survey of their sensory properties, health effects, antioxidant activity and analytical methods. An overview of the last decade. Molecules 2007, 12, 1679-1719. [CrossRef]

22. Casas, R.; Estruch, R.; Sacanella, E. The Protective Effects of Extra Virgin Olive Oil on Immune-mediated Inflammatory Responses. Endocr. Metab. Immune Disord. Drug Targets 2018, 18, 23-35. [CrossRef]

23. Pedan, V.; Popp, M.; Rohn, S.; Nyfeler, M.; Bongartz, A. Characterization of Phenolic Compounds and Their Contribution to Sensory Properties of Olive Oil. Molecules 2019, 24, 2401. [CrossRef]

24. Rizwan, S.; Benincasa, C.; Mehmood, K.; Anjum, S.; Mehmood, Z.; Alizai, G.H.; Azam, M.; Perri, E.; Sajjad, A. Fatty Acids and Phenolic Profiles of Extravirgin Olive Oils from Selected Italian Cultivars Introduced in Southwestern Province of Pakistan. J. Oleo Sci. 2019, 68, 33-43. [CrossRef]

25. Efsa Panel on Dietetic Products, Nutrition And Allergies (NDA). Scientific opinion on the substantiation of health claims related to polyphenols in olive and protection of LDL particles from oxidative damage (Id 1333, 1638, 1639, 1696, 2865), maintenance of normal blood HDL cholesterol concentrations (Id 1639), maintenance of normal blood pressure (Id 3781), "anti-inflammatory properties" (id 1882), "contributes to the upper respiratory tract health" (Id 3467) pursuant to article 13(1) of regulation (ec) no 1924/2006. EFSA J. 2011, 9, 2033.

26. Olivenöl. Available online: https://fddb.info/db/de/lebensmittel/naturprodukt_olivenoel/index.html (accessed on 29 November 2019).

27. Olive Oil Nutrition Facts. Available online: https://www.nutrition-and-you.com/olive-oil.html (accessed on 29 November 2019).

28. Olivenöl. Available online: http://www.ernaehrung.de/lebensmittel/de/Q120000/Olivenoel.php (accessed on 29 November 2019).

29. Bendinelli, B.; Masala, G.; Saieva, C.; Salvini, S.; Calonico, C.; Sacerdote, C.; Agnoli, C.; Grioni, S.; Frasca, G.; Mattiello, A.; et al. Fruit, vegetables, and olive oil and risk of coronary heart disease in Italian women: The EPICOR Study. Am. J. Clin. Nutr. 2011, 93, 275-283. [CrossRef] [PubMed] 
30. Romani, A.; Ieri, F.; Urciuoli, S.; Noce, A.; Marrone, G.; Nediani, C.; Bernini, R. Health Effects of Phenolic Compounds Found in Extra-Virgin Olive Oil, By-Products, and Leaf of Olea europaea L. Nutrients 2019, 11, 1776. [CrossRef] [PubMed]

31. Guasch-Ferré, M.; Hu, F.B.; Martínez-González, M.A.; Fitó, M.; Bulló, M.; Estruch, R.; Ros, E.; Corella, D.; Recondo, J.; Gómez-Gracia, E.; et al. Olive oil intake and risk of cardiovascular disease and mortality in the PREDIMED Study. BMC Med. 2014, 12, 78. [CrossRef]

32. Bogani, P.; Galli, C.; Villa, M.; Visioli, F. Postprandial anti-inflammatory and antioxidant effects of extra virgin olive oil. Atherosclerosis 2007, 190, 181-186. [CrossRef]

33. Visioli, F.; Caruso, D.; Grande, S.; Bosisio, R.; Villa, M.; Galli, G.; Sirtori, C.; Galli, C. Virgin Olive Oil Study (VOLOS): Vasoprotective potential of extra virgin olive oil in mildly dyslipidemic patients. Eur. J. Nutr. 2005, 44, 121-127. [CrossRef]

34. Carnevale, R.; Pignatelli, P.; Nocella, C.; Loffredo, L.; Pastori, D.; Vicario, T.; Petruccioli, A.; Bartimoccia, S.; Violi, F. Extra virgin olive oil blunt post-prandial oxidative stress via NOX2 down-regulation. Atherosclerosis 2014, 235, 649-658. [CrossRef]

35. Mitjavila, M.T.; Fandos, M.; Salas-Salvadó, J.; Covas, M.I.; Borrego, S.; Estruch, R.; Lamuela-Raventós, R.; Corella, D.; Martínez-Gonzalez, M.Á.; Sánchez, J.M.; et al. The Mediterranean diet improves the systemic lipid and DNA oxidative damage in metabolic syndrome individuals. A randomized, controlled, trial. Clin. Nutr. 2013, 32, 172-178. [CrossRef]

36. Perrone, M.A.; Gualtieri, P.; Gratteri, S.; Ali, W.; Sergi, D.; Muscoli, S.; Cammarano, A.; Bernardini, S.; Di Renzo, L.; Romeo, F. Effects of postprandial hydroxytyrosol and derivates on oxidation of LDL, cardiometabolic state and gene expression: A nutrigenomic approach for cardiovascular prevention. J. Cardiovasc. Med. 2019, 20, 419-426. [CrossRef]

37. Esposito, K.; Marfella, R.; Ciotola, M.; Di Palo, C.; Giugliano, F.; Giugliano, G.; D'Armiento, M.; D’Andrea, F.; Giugliano, D. Effect of a mediterranean-style diet on endothelial dysfunction and markers of vascular inflammation in the metabolic syndrome: A randomized trial. JAMA 2004, 292, 1440-1446. [CrossRef]

38. Davis, C.R.; Hodgson, J.M.; Woodman, R.; Bryan, J.; Wilson, C.; Murphy, K.J. A Mediterranean diet lowers blood pressure and improves endothelial function: Results from the MedLey randomized intervention trial. Am. J. Clin. Nutr. 2017, 105, 1305-1313. [CrossRef] [PubMed]

39. Storniolo, C.E.; Casillas, R.; Bulló, M.; Castañer, O.; Ros, E.; Sáez, G.T.; Toledo, E.; Estruch, R.; Ruiz-Gutiérrez, V.; Fitó, M.; et al. A Mediterranean diet supplemented with extra virgin olive oil or nuts improves endothelial markers involved in blood pressure control in hypertensive women. Eur. J. Nutr. 2017, 56, 89-97. [CrossRef] [PubMed]

40. European Association for Cardiovascular Prevention \& Rehabilitation; Reiner, Z.; Catapano, A.L.; De Backer, G.; Graham, I.; Taskinen, M.R.; Wiklund, O.; Agewall, S.; Alegria, E.; Chapman, M.J.; et al. ESC/EAS Guidelines for the management of dyslipidaemias: The Task Force for the management of dyslipidaemias of the European Society of Cardiology (ESC) and the European Atherosclerosis Society (EAS). Eur. Heart J. 2011, 32, 1769-1818. [CrossRef] [PubMed]

41. Hernáez, Á.; Castañer, O.; Goday, A.; Ros, E.; Pintó, X.; Estruch, R.; Salas-Salvadó, J.; Corella, D.; Arós, F.; Serra-Majem, L.; et al. The Mediterranean Diet decreases LDL atherogenicity in high cardiovascular risk individuals: A randomized controlled trial. Mol. Nutr. Food Res. 2017, 61, 1601015. [CrossRef]

42. Covas, M.I.; Nyyssönen, K.; Poulsen, H.E.; Kaikkonen, J.; Zunft, H.J.; Kiesewetter, H.; Gaddi, A.; de la Torre, R.; Mursu, J.; Bäumler, H.; et al. The effect of polyphenols in olive oil on heart disease risk factors: A randomized trial. Ann. Intern. Med. 2006, 145, 333-341. [CrossRef]

43. Violi, F.; Loffredo, L.; Pignatelli, P.; Angelico, F.; Bartimoccia, S.; Nocella, C.; Cangemi, R.; Petruccioli, A.; Monticolo, R.; Pastori, D.; et al. Extra virgin olive oil use is associated with improved post-prandial blood glucose and LDL cholesterol in healthy subjects. Nutr. Diabetes 2015, 5, e172. [CrossRef]

44. Carnevale, R.; Loffredo, L.; Del Ben, M.; Angelico, F.; Nocella, C.; Petruccioli, A.; Bartimoccia, S.; Monticolo, R.; Cava, E.; Violi, F. Extra virgin olive oil improves post-prandial glycemic and lipid profile in patients with impaired fasting glucose. Clin. Nutr. 2017, 36, 782-787. [CrossRef]

45. Schwingshackl, L.; Lampousi, A.M.; Portillo, M.P.; Romaguera, D.; Hoffmann, G.; Boeing, H. Olive oil in the prevention and management of type 2 diabetes mellitus: A systematic review and meta-analysis of cohort studies and intervention trials. Nutr. Diabetes 2017, 7, e262. [CrossRef] 
46. Qian, F.; Korat, A.A.; Malik, V.; Hu, F.B. Metabolic Effects of Monounsaturated Fatty Acid-Enriched Diets Compared with Carbohydrate or Polyunsaturated Fatty Acid-Enriched Diets in Patients with Type 2 Diabetes: A Systematic Review and Meta-analysis of Randomized Controlled Trials. Diabetes Care 2016, 39, 1448-1457. [CrossRef]

47. Schwingshackl, L.; Strasser, B. High-MUFA diets reduce fasting glucose in patients with type 2 diabetes. Ann. Nutr. Metab. 2012, 60, 33-34. [CrossRef]

48. Schwingshackl, L.; Strasser, B.; Hoffmann, G. Effects of monounsaturated fatty acids on cardiovascular risk factors: A systematic review and meta-analysis. Ann. Nutr. Metab. 2011, 59, 176-186. [CrossRef]

49. Salas-Salvadó, J.; Bulló, M.; Babio, N.; Martínez-González, M.Á.; Ibarrola-Jurado, N.; Basora, J.; Estruch, R.; Covas, M.I.; Corella, D.; Arós, F.; et al. Reduction in the incidence of type 2 diabetes with the Mediterranean diet: Results of the PREDIMED-Reus nutrition intervention randomized trial. Diabetes Care 2011, 34, 14-19. [CrossRef] [PubMed]

50. Salas-Salvadó, J.; Bulló, M.; Estruch, R.; Ros, E.; Covas, M.I.; Ibarrola-Jurado, N.; Corella, D.; Arós, F.; Gómez-Gracia, E.; Ruiz-Gutiérrez, V.; et al. Prevention of diabetes with Mediterranean diets: A subgroup analysis of a randomized trial. Ann. Intern. Med. 2014, 160,1-10. [CrossRef] [PubMed]

51. Carnevale, R.; Silvestri, R.; Loffredo, L.; Novo, M.; Cammisotto, V.; Castellani, V.; Bartimoccia, S.; Nocella, C.; Violi, F. Oleuropein, a component of extra virgin olive oil, lowers postprandial glycaemia in healthy subjects. Br. J. Clin. Pharmacol. 2018, 84, 1566-1574. [CrossRef] [PubMed]

52. Menendez, J.A.; Lupu, R. Mediterranean dietary traditions for the molecular treatment of human cancer: Anti-oncogenic actions of the main olive oil's monounsaturated fatty acid oleic acid (18:1n-9). Curr. Pharm. Biotechnol. 2006, 7, 495-502. [CrossRef] [PubMed]

53. Ramirez-Tortosa, C.; Sanchez, A.; Perez-Ramirez, C.; Quiles, J.L.; Robles-Almazan, M.; Pulido-Moran, M.; Sanchez-Rovira, P.; Ramirez-Tortosa, M. Hydroxytyrosol Supplementation Modifies Plasma Levels of Tissue Inhibitor of Metallopeptidase 1 in Women with Breast Cancer. Antioxidants 2019, 8, 393. [CrossRef]

54. Storniolo, C.E.; Martínez-Hovelman, N.; Martínez-Huélamo, M.; Lamuela-Raventos, R.M.; Moreno, J.J. Extra Virgin Olive Oil Minor Compounds Modulate Mitogenic Action of Oleic Acid on Colon Cancer Cell Line. J. Agric. Food Chem. 2019, 67, 11420-11427. [CrossRef]

55. Polini, B.; Digiacomo, M.; Carpi, S.; Bertini, S.; Gado, F.; Saccomanni, G.; Macchia, M.; Nieri, P.; Manera, C.; Fogli, S. Oleocanthal and oleacein contribute to the in vitro therapeutic potential of extra virgin oil-derived extracts in non-melanoma skin cancer. Toxicol. In Vitro 2018, 52, 243-250. [CrossRef]

56. Psaltopoulou, T.; Kosti, R.I.; Haidopoulos, D.; Dimopoulos, M.; Panagiotakos, D.B. Olive oil intake is inversely related to cancer prevalence: A systematic review and a meta-analysis of 13,800 patients and 23,340 controls in 19 observational studies. Lipids Health Dis. 2011, 10, 127. [CrossRef]

57. Sieri, S.; Krogh, V.; Pala, V.; Muti, P.; Micheli, A.; Evangelista, A.; Tagliabue, G.; Berrino, F. Dietary patterns and risk of breast cancer in the ORDET cohort. Cancer Epidemiol. Biomark. Prev. 2004, 13, 567-572.

58. Toledo, E.; Salas-Salvadó, J.; Donat-Vargas, C.; Buil-Cosiales, P.; Estruch, R.; Ros, E.; Corella, D.; Fitó, M.; Hu, F.B.; Arós, F.; et al. Mediterranean Diet and Invasive Breast Cancer Risk Among Women at High Cardiovascular Risk in the PREDIMED Trial: A Randomized Clinical Trial. JAMA Intern. Med. 2015, 175, 1752-1760. [CrossRef]

59. Fogli, S.; Arena, C.; Carpi, S.; Polini, B.; Bertini, S.; Digiacomo, M.; Gado, F.; Saba, A.; Saccomanni, G.; Breschi, M.C.; et al. Cytotoxic Activity of Oleocanthal Isolated from Virgin Olive Oil on Human Melanoma Cells. Nutr. Cancer 2016, 68, 873-877. [CrossRef]

60. Parkinson, L.; Keast, R. Oleocanthal, a phenolic derived from virgin olive oil: A review of the beneficial effects on inflammatory disease. Int. J. Mol. Sci. 2014, 15, 12323-12334. [CrossRef]

61. Rodríguez-Hernández, H.; Simental-Mendía, L.E.; Rodríguez-Ramírez, G.; Reyes-Romero, M.A. Obesity and inflammation: Epidemiology, risk factors, and markers of inflammation. Int. J. Endocrinol. 2013, 2013, 678159. [CrossRef]

62. Tajima, H.; Pawankar, R. Obesity and adiposity indicators in asthma and allergic rhinitis in children. Curr. Opin. Allergy Clin. Immunol. 2019, 19, 7-11. [CrossRef]

63. Scoditti, E.; Carpi, S.; Massaro, M.; Pellegrino, M.; Polini, B.; Carluccio, M.A.; Wabitsch, M.; Verri, T.; Nieri, P.; De Caterina, R. Hydroxytyrosol Modulates Adipocyte Gene and miRNA Expression Under Inflammatory Condition. Nutrients 2019, 11, 2493. [CrossRef] 
64. Nocella, C.; Cammisotto, V.; Fianchini, L.; D'Amico, A.; Novo, M.; Castellani, V.; Stefanini, L.; Violi, F.; Carnevale, R. Extra Virgin Olive Oil and Cardiovascular Diseases: Benefits for Human Health. Endocr. Metab. Immune Disord. Drug Targets 2018, 18, 4-13. [CrossRef]

65. Garcia-Marcos, L.; Castro-Rodriguez, J.A.; Weinmayr, G.; Panagiotakos, D.B.; Priftis, K.N.; Nagel, G. Influence of Mediterranean diet on asthma in children: A systematic review and meta-analysis. Pediatr. Allergy Immunol. 2013, 24, 330-338. [CrossRef]

66. Papamichael, M.M.; Itsiopoulos, C.; Susanto, N.H.; Erbas, B. Does adherence to the Mediterranean dietary pattern reduce asthma symptoms in children? A systematic review of observational studies. Public Health Nutr. 2017, 20, 2722-2734. [CrossRef]

67. Cazzoletti, L.; Zanolin, M.E.; Spelta, F.; Bono, R.; Chamitava, L.; Cerveri, I.; Garcia-Larsen, V.; Grosso, A.; Mattioli, V.; Pirina, P.; et al. Dietary fats, olive oil and respiratory diseases in Italian adults: A population-based study. Clin. Exp. Allergy 2019, 49, 799-807. [CrossRef]

68. Bonura, A.; Vlah, S.; Longo, A.; Bulati, M.; Melis, M.R.; Cibella, F.; Colombo, P. Hydroxytyrosol modulates Par j 1-induced IL-10 production by PBMCs in healthy subjects. Immunobiology 2016, 221, 1374-1377. [CrossRef]

69. Lai, C.K.; Beasley, R.; Crane, J.; Foliaki, S.; Shah, J.; Weiland, S.; International Study of Asthma and Allergies in Childhood Phase Three Study Group. Global variation in the prevalence and severity of asthma symptoms: Phase three of the International Study of Asthma and Allergies in Childhood (ISAAC). Thorax 2009, 64, 476-483. [CrossRef]

70. Aparicio-Soto, M.; Redhu, D.; Sánchez-Hidalgo, M.; Fernández-Bolaños, J.G.; Alarcón-de-la-Lastra, C.; Worm, M.; Babina, M. Olive-Oil-Derived Polyphenols Effectively Attenuate Inflammatory Responses of Human Keratinocytes by Interfering with the NF-кB Pathway. Mol. Nutr. Food Res. 2019. [CrossRef]

(C) 2019 by the authors. Licensee MDPI, Basel, Switzerland. This article is an open access article distributed under the terms and conditions of the Creative Commons Attribution (CC BY) license (http://creativecommons.org/licenses/by/4.0/). 